American Journal of Pharmaceutical Education 2019; 83 (4) Article 6950.

\title{
BRIEF
}

\section{Identifying and Mapping Skill Development Opportunities Through Pharmacy Student Organization Involvement}

\author{
Jacqueline M. Zeeman, PharmD, ${ }^{\mathrm{a}}$ Antonio A. Bush, PhD, ${ }^{\mathrm{a}}$ Wendy C. Cox, PharmD, ${ }^{\mathrm{a}}$ \\ Katie Buhlinger, PharmD, ${ }^{a}$ Jacqueline E. McLaughlin, $\mathrm{PhD}^{\mathrm{a}}$ \\ ${ }^{a}$ UNC Eshelman School of Pharmacy, University of North Carolina at Chapel Hill, Chapel Hill, North Carolina \\ Submitted January 12, 2018; accepted May 30, 2018; published May 2019.
}

\begin{abstract}
Objective. To describe a process for identifying skills that students can gain through co-curricular involvement and to map these skills to curricular outcomes.

Methods. This pilot study used a mixed-methods approach involving document reviews, student involvement surveys, and focus groups/interviews to evaluate skill development opportunities in three pharmacy student organizations. Investigators reviewed key documents (eg, student organization websites, annual review forms) to identify skills emphasized by the organization. Student participants completed modified Extracurricular Involvement Inventory surveys to measure the intensity of their student organization involvement. Two student focus groups, one student leader focus group and one general student member focus group, were held for each student organization. Interviews were conducted with each student organization's faculty advisor. Data sources were triangulated to identify and map skill development opportunities to program core competencies.

Results. Six of nine core competencies were identified as skills pharmacy students can develop through involvement in the pilot student organizations. All three organizations provided opportunities for members to develop communication skills and in-depth knowledge and proficient skills of the discipline of pharmacy. Two organizations provided opportunities for students to develop collaboration skills.

Conclusion. A mixed-methods approach can be used to identify and map skills that students can develop through co-curricular involvement. This approach provides several advantages: objective evaluation and triangulation of skill development opportunities, evaluation of students' involvement, and identification of linkages between the co-curriculum and curriculum in the context of curricular outcomes.
\end{abstract}

Keywords: co-curricular, student organizations, skill development, pharmacy, health professions

\section{INTRODUCTION}

Increased emphasis has been placed on the value and impact of co-curricular experiences in the professional development of pharmacy students. ${ }^{1,2}$ As supported by the 2008-2009 Argus Commission and the 2009 Council of Faculties Task Force report, it is critical that schools and colleges of pharmacy contribute to the growth of students who will become change agents in the continuously evolving health care system. ${ }^{3,4}$ Professional skills, abilities, and behaviors (eg, teamwork, collaboration, communication) are becoming increasingly important, in addition to knowledge acquisition, to function effec-

Corresponding Author: Jacqueline E. McLaughlin, UNC Eshelman School of Pharmacy, University of North Carolina at Chapel Hill, 329 Beard Hall, Chapel Hill, NC 27599. Tel: 919-966-4557. E-mail: jacqui_mclaughlin@unc.edu tively within the health care team and to serve as change agents in the pharmacy profession. ${ }^{1-4}$ While it is important that student development experiences are made available through the core curriculum, student involvement in co-curricular activities, such as pharmacy student organizations, provide unique opportunities for pharmacy students to develop these professional skills. ${ }^{5}$

In pharmacy education, student organizations, consisting of both pharmacy- and non-pharmacy-related organizations, are voluntary out-of-class activities that play an integral role in the education process. ${ }^{6}$ Student organizations, along with other non-compulsory activities outside the curriculum that complement learning and development considered critical to preparing students for the workplace, are termed as "co-curriculum." ${ }^{\text {"Stu- }}$ dent organization involvement is a multi-dimensional construct that includes academic, social, and political 


\section{American Journal of Pharmaceutical Education 2019; 83 (4) Article 6950.}

layers. ${ }^{7}$ Astin, a pioneer in student involvement research, defines student involvement as ". . . the amount of physical and psychological energy that the student devotes to the academic experience."7 This physical and psychological energy emphasizes actions and behaviors and can be viewed as the quantity and quality of the student's involvement in the academic experience (eg, studying, student organization involvement). ${ }^{7}$ Although literature describes various types of evidence supporting undergraduate student skill development through involvement in the co-curriculum, ${ }^{7-9}$ much of the pharmacy education research relies on students' self-reported beliefs about skill development and often focuses specifically on student leaders. ${ }^{5,10-12}$ The literature suggests that a culture of voluntary and non-compulsory student involvement in the co-curriculum is already embedded in pharmacy schools. ${ }^{2,5,6,10-12}$ Reflecting this rich culture and recognizing the value of these experiences, the Accreditation Council for Pharmacy Education (ACPE) Standards 2016 include the co-curriculum and highlight that co-curricular activities should augment and be linked to the curriculum. ${ }^{1}$ Further work is needed to better understand what types of skills student pharmacists can develop through co-curriculum involvement (eg, student organization involvement), and how those skills align with the competencies and outcomes emphasized by a school or college's curriculum.

As growing emphasis is placed on developing and assessing the co-curriculum in pharmacy education, strategies for evaluating co-curricular activities and determining how they complement the learning that occurs in the formal curriculum must be identified. ${ }^{1,2}$ The purpose of this study was to describe a process for identifying the skills that pharmacy students can develop through co-curricular involvement in pharmacy student organizations. By mapping these skills to curricular outcomes, a more complete understanding of how the co-curriculum complements the formal curriculum could be illustrated.

\section{METHODS}

Embracing the philosophy that co-curricular involvement complements and advances the learning that occurs within the formal didactic and experiential curriculum, ${ }^{1}$ we sought to identify opportunities in which students are able to develop the skills outlined in the University of North Carolina at Chapel Hill (UNC) Eshelman School of Pharmacy's Doctor of Pharmacy (PharmD) program core competencies through student organization involvement. This work was done in the context of the school's transformed PharmD curricu$\operatorname{lum}^{13}$ and the program's core competencies were used to demonstrate how the co-curriculum complements the formal curriculum. These nine PharmD program core competencies include: in-depth knowledge and proficient skills of the discipline of pharmacy, accessing and analyzing information, critical thinking and problem solving, communication, collaboration and influence, adaptability, initiative, curiosity and inquisitiveness, and professionalism.

Astin's theory of student involvement articulates five basic postulates, three of which guided our efforts. The first postulate suggests "involvement refers to the investment of physical and psychological energy in various objects." Thus, our efforts examined the specific activities (ie, object) of student investment in student organizations. The second postulate states "regardless of its object, involvement occurs along a continuum." Thus, the degree of student involvement in the co-curriculum will vary among our students (eg, student leader vs student member). The third postulate states "involvement has both quantitative and qualitative features."7 Thus, involvement was measured quantitatively (ie, amount of time spent involved in the student organization) and qualitatively (ie, the quality of time spent with the student organization).

To develop a sustainable assessment process for identifying skills developed through pharmacy student organization involvement, three student organizations were invited to participate in a pilot study. These three pharmacy student organizations were intentionally selected as they each had a unique focus (ie, special interest, professional fraternity, and service). This pilot study was considered exempt from further review by the Institutional Review Board at the University of North Carolina at Chapel Hill.

A three-component mixed-methods approach was used to collect the pilot data in Spring 2016. ${ }^{14}$ The first component was a document review of organization websites and annual review forms submitted to the school's Office of Curricular and Student Affairs (OCSA). The document review was used to identify the organization's mission and any skills emphasized by the organization.

The second component of the mixed-methods approach involved student focus groups and faculty interviews. Three types of focus groups or interviews were held separately with recruited participants for each pilot organization: faculty advisor interview, student leader focus group, and general student member focus group. In other words, a total of nine interviews were conducted, with three focus group/interviews being conducted for each of the three pilot organizations.

OCSA identified faculty advisors and student organization leaders for the three pilot organizations and student leaders provided student-organization rosters of general 


\section{American Journal of Pharmaceutical Education 2019; 83 (4) Article 6950.}

members. All pilot organization faculty advisors agreed to participate, and student participants were recruited by convenience sample for each pilot organization. The three groups for each pilot student organization participated in separate 60-minute focus group/interviews. The purpose of the faculty advisor interview was to collect the advisor's insight of the skills pharmacy students can develop through participation in the organization. The purpose of the student leader focus group was to provide an overview of all activities within the student organization. Notably, the student leader focus group was intentionally separate from the general member focus group to reduce the bias potentially introduced by the student leader given their intimate knowledge and insight into all the programs offered within the organization. The purpose of the general student member focus group was to determine the awareness of skills students can develop as a result of participating in the student organization. The interviewers used a semistructured interview protocol in each focus group/interview that was audio recorded and then transcribed by the third party, Rev.com. The semi-structured interview protocol primed participants to discuss what skills they think students can develop through involvement in the pharmacy student organization, how students can develop these skills, and examples of when they noticed a pharmacy student developed one or more of these skills during a student organization event.

As the third and final component of the mixedmethods approach, all student participants completed a modified Extracurricular Involvement Inventory (EII) during the focus group. ${ }^{15}$ The EII is a tool used to quantify students' self-reported hours spent in organized activities and student organizations and measures various quality dimensions of the student's involvement, including meeting participation and program or activity attendance. ${ }^{15}$ A student's total score of involvement in all organized student activities, or EII score, is the product of the scaled quantity index and the sum of the quality index. ${ }^{15}$ This tool has been previously used in pharmacy to describe the types of student organizations students participate in and their level of involvement. ${ }^{6}$ For the purposes of this study, the EII was modified to measure a student's involvement in only the student organization of interest. Additionally, the types of organizations were modified to more closely represent common pharmacy student organizations (Appendix 1). Descriptive statistics were used to analyze the EII results, including the quantity dimension, quality dimension, and the overall involvement intensity score. Each student's total EII score was calculated using the formula outlined by Winston and Massaro: (Scaled Quantity Dimension) $\mathrm{x}$ (Sum of Quality Dimensions). ${ }^{15}$

To ensure the trustworthiness of the data analysis process, a dependability audit was used to document study efforts. ${ }^{16}$ More specifically, the dependability audit documented each step of the data collection and analysis process, including the rationale for decisions made in conducting the study. Additionally, multiple coders were involved to promote trustworthiness of the data analysis process. Two researchers coded one transcript to align the coding efforts and reach consensus on the meaning of the codebook items, which was guided by the school's core competencies (Table 1). In addition to the predetermined codebook items, the researchers were responsive to emerging codes within the data. After collaboratively coding the first transcript, intentional discussion, debate, and clarification were used to reach agreement in the coding. ${ }^{17}$ Upon reaching consensus on the first transcript, the two researchers separately coded the remaining transcripts and met to discuss any areas of disagreement. Upon reaching consensus on the final two transcripts, the transcripts were externally audited by a member of the research team. No areas of disagreement were identified during the external audit. Researchers

Table 1. Skill Development Opportunities Mapped to Pilot Student Organizations

Student Organization A $\quad$ Student Organization B $\quad$ Student Organization C (Special Interest)

(Professional Fraternity)

Accessing and analyzing information

Adaptability

Collaboration and influence

Communication

Critical thinking and problem solving

Curiosity and inquisitiveness

In-depth knowledge and proficient skills

of the discipline of pharmacy

Initiative

Professionalism 


\section{American Journal of Pharmaceutical Education 2019; 83 (4) Article 6950.}

identified and triangulated the qualitative themes to identify the skills students have the opportunity to develop through participation in the pharmacy student organization.

\section{RESULTS}

Of the focus group participants, the majority of general student members were first-year pharmacy (P1) students $(66.7 \%$ to $100 \%$ per student organization) while the majority of student leaders were third-year pharmacy (P3) students (Student Organization B: 100\%, Student Organization C: $75 \%$ ), with the exception of Student Organization A (33.3\%) (Table 2). Across all three organizations, modified EII results indicated that student leaders had higher levels of involvement compared to general student members (Table 2). The median modified EII score for all pharmacy students, both leaders and general members, was 9.0 in Student Organization A, 10.0 in Student Organization B, and 11.0 in Student Organization $\mathrm{C}$ (Table 2).

Six of the school's nine core competencies were identified as skill development opportunities in the pilot pharmacy student organizations (Table 1). Communication and in-depth knowledge and proficient skills of the discipline of pharmacy were present in all three organizations; collaboration and influence in two organizations; and accessing and analyzing information, critical thinking and problem solving, and adaptability each in one organization. Curiosity and inquisitiveness, initiative, and professionalism were not identified as skills emphasized within any of the pilot organizations (Table 1). Representative quotes from the focus group/interviews for each skill are provided in Table 3.

\section{DISCUSSION}

This study is one of the first to describe a process for identifying skills students can develop through student organization involvement in the co-curriculum and to map these skills to curricular outcomes. By mapping these skills to the school's program core competencies, skill development opportunities within the co-curriculum that complement the formal curriculum can be identified. Curriculum and assessment leadership can use this information to inform opportunities for curricular and/or co-curricular development while providing student affairs professionals with greater insight into existing student organization programs.

Additionally, our data suggest that various skill development opportunities may exist in different student organizations. Recognizing that student organizations have distinct initiatives and provide different co-curricular activities, we would expect that various core competencies would be emphasized across different student organizations. An opportunity exists to provide a map of the skill development opportunities that are available through student organization involvement in the co-curriculum to students and faculty. A co-curricular map can equip students with information to support their desire for identifying additional skill development opportunities outside the curriculum and empower them to tailor these opportunities to meet their skill development needs. Additionally, this information can be used by faculty advisors to guide students who need additional exposure and development to specific opportunities within the cocurriculum that emphasize these skills. Future research may consider identifying the level or degree at which skills are emphasized across student organizations and integrating these findings into the cocurricular map shared with students and faculty.

Utilization of a mixed-methods approach including student involvement surveys, student focus groups with pharmacy organization members and leaders, and interviews with faculty advisors provides several advantages. These advantages include, but are not limited to, the objective evaluation of skill development opportunities through student organization involvement, evaluation of students' quantitative and qualitative involvement within the organization, and co-curricular assessment that can be mapped for various audiences including students, faculty advisors, administrators, and accreditors. While this pilot study mapped skills to the UNC Eshelman School of Pharmacy PharmD program core competencies, this methodology can be applied to evaluate other outcomes of interest (eg, accreditation standards); therefore, this process can be extrapolated to other institutions to evaluate their unique co-curriculum and cocurricular activities.

Previous efforts to investigate skills gained through student organization involvement have been reported. ${ }^{10,12,18}$ Kiersma and colleagues evaluated student perceptions of the contribution of extracurricular activities to personal skill development. The top skills students reported developing were responsibility, helping others, getting along with others, organizing work and projects, and understanding others' points of view. ${ }^{18}$ Bradford and colleagues evaluated the relationship between self-reported professionalism and student involvement in pharmacy organizations, and they found $94 \%$ of student respondents claimed involvement in pharmacy organizations played a role in their professional development. ${ }^{10}$ Ho and colleagues found that one primary reason students reported extracurricular activity involvement was for professional development. ${ }^{12}$ 
American Journal of Pharmaceutical Education 2019; 83 (4) Article 6950.

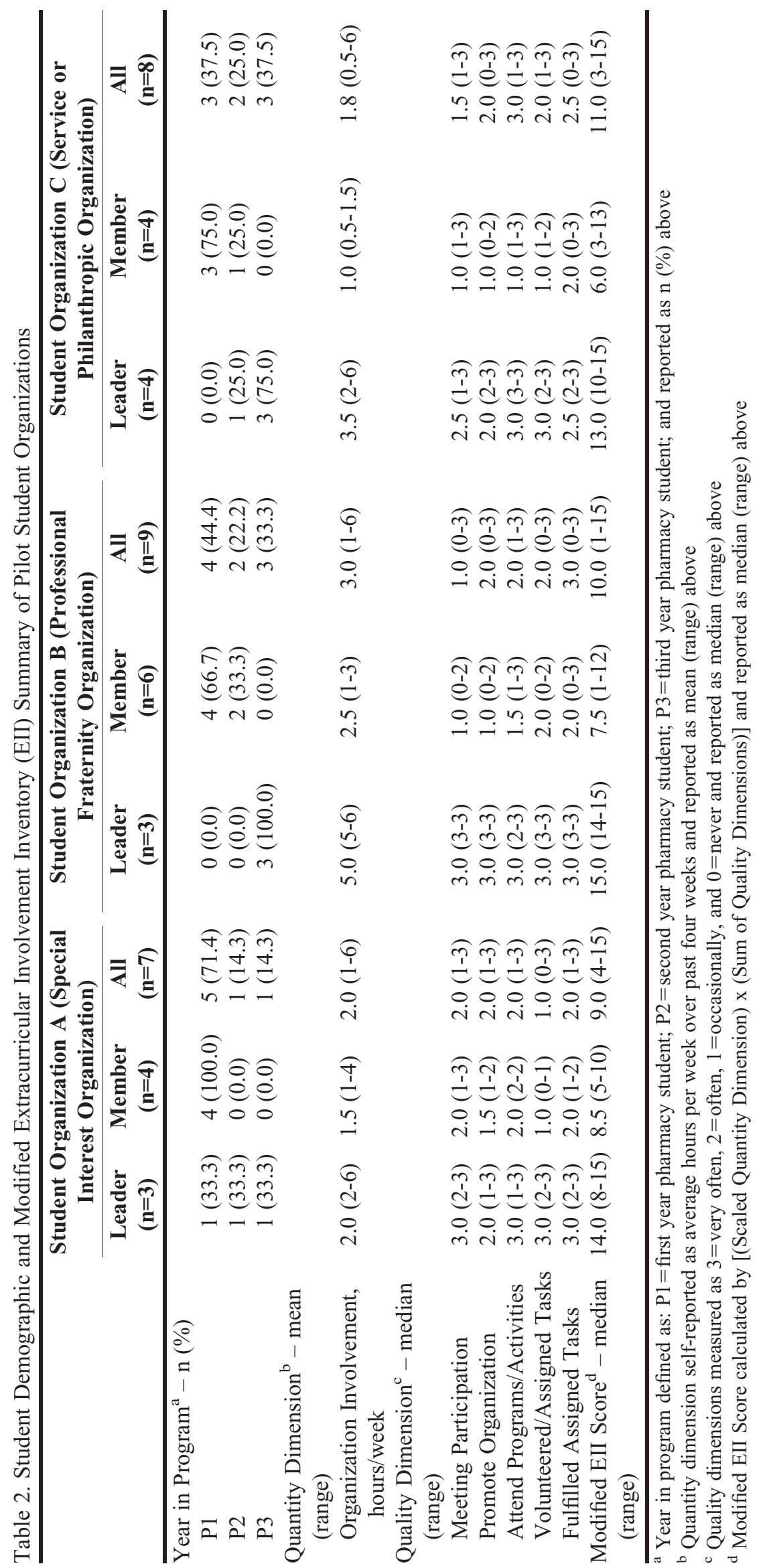


American Journal of Pharmaceutical Education 2019; 83 (4) Article 6950.
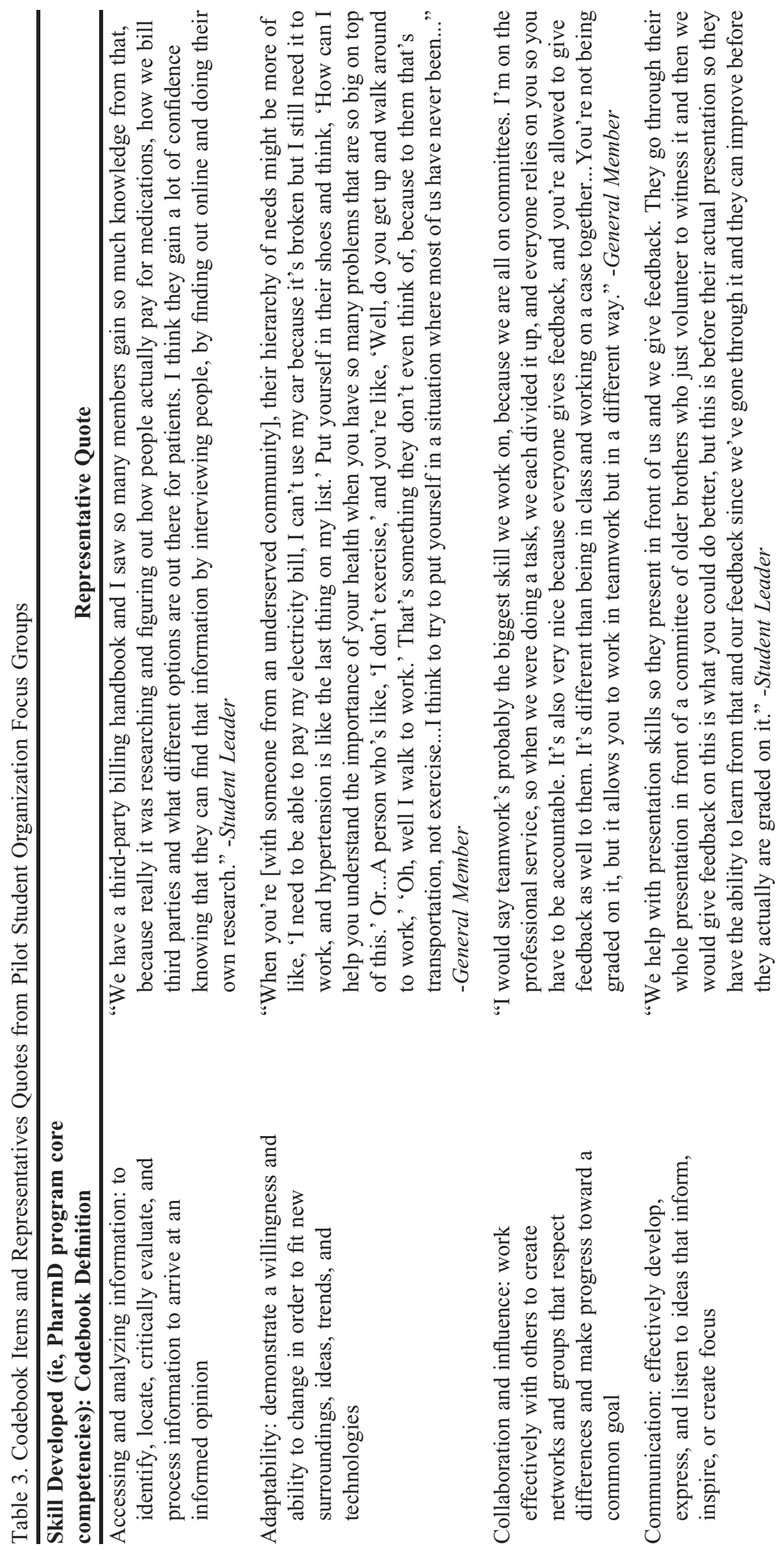

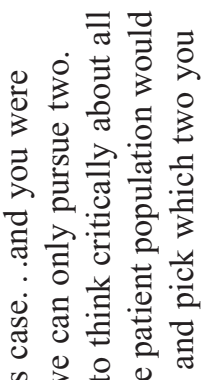

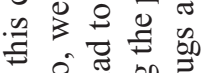

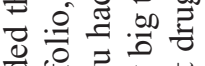

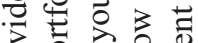

일

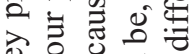

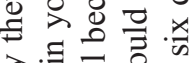

구용

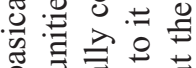

Ð

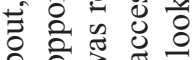

ส ชิ

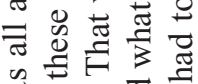

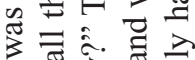

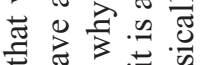

I

สี పี

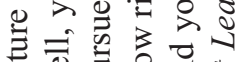

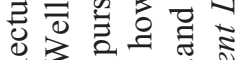

«

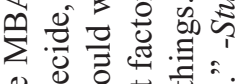

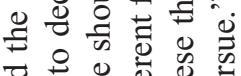

艺艺

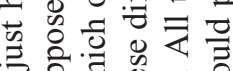

๖
壱㫄 콕 矛 응 $3 \stackrel{0}{0}$ 궁요. \# $\cong$ of 응

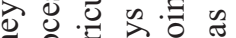

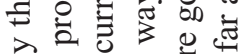

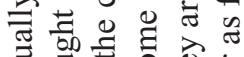
ڤ

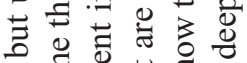
क छ

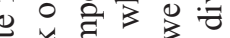

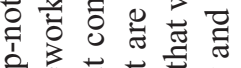

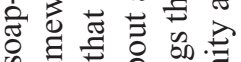
๙ 尝异

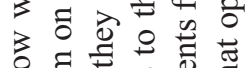

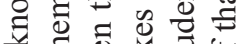

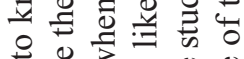
०

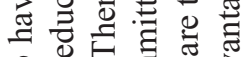

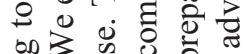
.

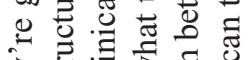

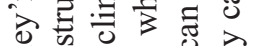
岳导

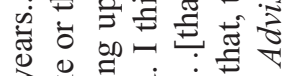

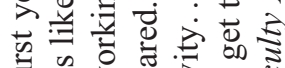

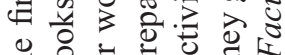
음

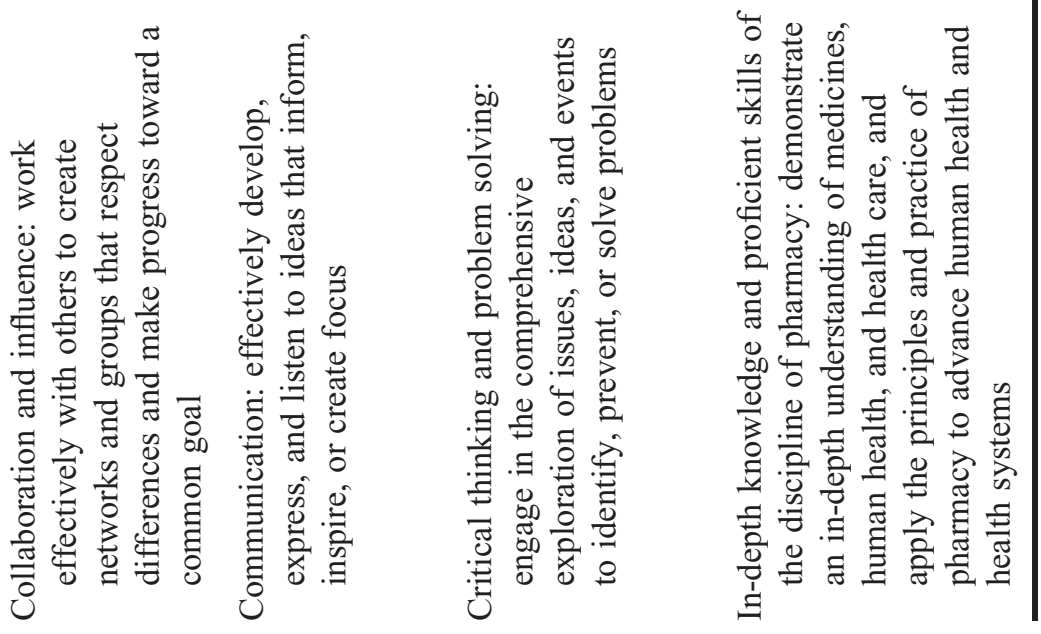




\section{American Journal of Pharmaceutical Education 2019; 83 (4) Article 6950.}

While these reports highlight the opportunities available for pharmacy students in student organizations, a limitation is the reliance on student self-reported benefits provided via online survey and that the skills identified were not explicitly linked to curricular outcomes.

Other health professions disciplines have also investigated the skill development opportunities available for students in co-curricular activities. Masella outlined the impact of extracurricular learning in the hidden curriculum within dental education and highlighted the value of organizations in students' professional development. ${ }^{19}$ Jamal used semi-structured interviews to evaluate interpersonal skills and professional behaviors in undergraduate medical students. Students acknowledged gains in communication, teamwork, managerial skills, problem solving, leadership, reflection and self-reflection, responsibility, confidence, respect, and sharing. Jamal concluded that these findings confirm that participation in extracurricular activities promotes the gain of interpersonal and professional behaviors in medical students. ${ }^{20}$ While these efforts evaluate the skill development opportunities within student organization involvement in other health professions programs, there is little research on what students are gaining from their experiences in cocurricular activities outside leadership development opportunities in pharmacy. Of the research conducted in pharmacy and the health professions literature, much of it relies on student self-reported benefits provided via survey and fails to map skills gained through such experiences to curricular outcomes.

In this study, our mixed-methods approach provided several benefits. ${ }^{14}$ By using multiple focus groups composed of different types of students involved in the organization (eg, student leaders and student members), we were able to identify opportunities for student development within the student narrative. Through data source triangulation, we were able to reduce the biases of student self-reported benefits. ${ }^{21}$ Furthermore, semi-structured interview protocols and probing questions assisted with identifying specific skills students may develop and created an opportunity to explore responses in further detail and triangulate skill development opportunities that otherwise would not have been available through survey methodology. The modified EII provided additional details regarding students' involvement and assisted with evaluating the degree of involvement across the pilot student organizations and among student leaders and general members within each organization.

Although this study describes an assessment methodology and a mapping approach of the co-curriculum to curricular outcomes, its implementation is limited to a single institution and its evaluation to three pilot student organizations. Selection bias cannot be ruled out as the pilot student organizations and student participants were identified by a convenience sample. Additionally, student reflections of skill development opportunities frequently involved examples of organization activities, programs, and events; however, a summary of these activities, programs, and events were limited to student recall during the focus group. Future efforts to expand this work will include all student organizations at the school and will require a list of the organization's activities, programs, and events be provided beforehand.

Using the school's PharmD program core competencies to map the skills available in the co-curriculum, there were limitations found in applying the professionalism core competency to our evaluation. The school's program core competencies define professionalism as "[the ability to] uphold the highest standards of professional and ethical behavior and act appropriately, thoughtfully, and with integrity at all times." 22 Through the coding process, we recognized the difficulty in applying this core competency as defined consistently to specific actions and behaviors. Future efforts will aim to more clearly define the attitudes, skills, and behaviors representative of professionalism so that this skill can be effectively evaluated in future co-curricular assessment efforts.

While this methodology used a mixed-methods approach to identify skill development opportunities through student organization involvement, the process was resource intensive. ${ }^{14}$ Future efforts will consider staggering the focus group/interviews across semesters and/or academic years to reduce the time required to conduct the meetings and evaluate the qualitative findings. Furthermore, it is imperative to note that the use of frequencies of qualitative codes was not used to determine themes. Rather, our study explored whether an opportunity to develop a skill was present within a student organization.

Another limitation in this pilot approach was that faculty advisors' greatest connection to the organization was through the student leadership team, which noticeably limited their ability to reflect on skill development opportunities available for general student members. Additionally, underclassmen, specifically P1 students, had limited experience with the student organization and were thus less able to articulate the opportunities to develop skills through the various organizational activities and programs. Furthermore, the document review provided limited value to the data analysis and research efforts, as most of this information was not specific to the local chapter and/or did not identify specific skill development opportunities. Future efforts will not involve document reviews or faculty advisor interviews and will continue to aim for diverse class representation among student participants. 


\section{American Journal of Pharmaceutical Education 2019; 83 (4) Article 6950.}

While utilization of a modified EII provided valuable information regarding the quantity and quality of a student's involvement in the pharmacy organization, it was modified from its original form to best apply to the student pharmacist experience and was adapted to only measure a student's involvement in the organization of interest rather than all student organizations and activities (Appendix 1). ${ }^{15}$ Consequently, the quantity dimension scoring of the modified EII limited the differentiation among students. As described by Winston and Massaro, the quantity dimension of the inventory is scored as: zero points for zero hours/week, one point for one to eight hours/week, two points for nine to 16 hours/week, etc. ${ }^{15}$ Modification to only measure a student's involvement in the student organization of interest resulted in all pilot student participants scoring one point on the quantity dimension (ie, 1-8 hours/ week spent on student organization activities). Modifications to the quantity dimension scoring will be considered in future efforts to further differentiate student involvement. While our pilot efforts used the modified EII to measure student involvement in the student organization of interest, future efforts may consider using this tool to evaluate the intensity of pharmacy student involvement in the co-curriculum as whole.

\section{CONCLUSION}

This study suggests that utilization of a mixedmethods approach involving student involvement surveys and student focus groups can identify skill development opportunities offered through pharmacy student organization involvement in the co-curriculum. By mapping these skills to curricular outcomes, a more complete understanding of how the co-curriculum complements the curriculum can be portrayed. This approach provides several advantages: objective evaluation and triangulation of skill development opportunities that are available through participation in pharmacy student organizations, evaluation of students' involvement within the student organization, and co-curricular mapping for various audiences including students, faculty, administrators, and accreditors. This approach can be extrapolated to other schools and colleges of pharmacy, as well as other health professions' education programs, as increased emphasis is placed on the importance and value of skill development in addition to knowledge acquisition in the student learning environment. Given the voluntary nature of co-curricular activities, such as student organization involvement, and the complexities of measuring skill development in non-compulsory activities, consideration should be given to the expectation on students to ensure they develop key skills and knowledge to meet program outcomes through activities undertaken in their own time outside the required curriculum. The process described here provides insight into opportunities for further identifying, assessing, and mapping the skill development opportunities available for all students through participation and involvement in student organizations within the co-curriculum.

\section{REFERENCES}

1. Accreditation Council for Pharmacy Education. Accreditation standards and key elements for the professional program in pharmacy leading to the Doctor of Pharmacy degree. Standards 2016. https:// www.acpe-accredit.org/pdf/Standards2016FINAL.pdf. Accessed June 29, 2017.

2. Patel UJ, Mediwala KN, Smith KM, Taylor S, Romanelli F. Carpe diem! Seizing the rise of co-curricular experiences. Am J Pharm Educ. 2017;81(8):Article 6702.

3. Kerr RA, Beck DE, Doss J, et al. Building a sustainable system of leadership development for pharmacy: report of the 2008-2009 Argus commission. Am J Pharm Educ. 2009;73(Suppl):Article S5.

4. Ross LE, Janke KK, Boyle CJ, et al. Preparation of faculty members and students to be citizen leaders and pharmacy advocates. Am J Pharm Educ. 2013;77(10):Article 220.

5. Phillips JA, McLaughlin MM, Gettig JP, Fajiculay JR, Advincula MR. An analysis of motivation factors for students' pursuit of leadership positions. Am J Pharm Educ. 2015;79(1):Article 8. 6. Cox ER, Krueger KP, Murphy JE. Pharmacy student involvement in student organizations. J Pharm Teach. 1998;6(3):9-18.

7. Astin AW. Student involvement: a developmental theory for higher education. J Coll Stud Pers. 1984;25(4):297-308.

8. Bodey KJ. Join the club: perceived benefits of participating in professional student organizations. IAHPERD Journal 2008;37(2):8-11.

9. Fisher DR. Educating engineers for the $21^{\text {st }}$ century: a framework for skill development through co-curricular and extracurricular involvement [master's thesis]. Cambridge, MA: Mass Inst of Tech; 2013.

10. Bradford D, Watmore P, Hammer D, Warholak TL. The relationship between self-reported professionalism and student involvement in pharmacy organizations at one college of pharmacy: an exploratory analysis. Curr Pharm Teach Learn. 2011;3(4):283289.

11. Chesnut R, Tran-Johnson J. Impact of a student leadership development program. Am J Pharm Educ. 2013;77(10):Article 225.

12. Ho MJ, Chan E, Fan-Havard P, Thompson C, Hess JM. The effects of leadership involvement and part-time employment on pharmacy student academic performance. Pharm Educ.

2014;14(1):57-63.

13. Roth MT, Mumper RJ, Singleton SF, et al. A renaissance in pharmacy education at the University of North Carolina at Chapel Hill. N C Med J. 2014;75(1):48-52.

14. McLaughlin JE, Bush AA, Zeeman JM. Mixed methods: expanding research methodologies in pharmacy education. Curr Pharm Teach Learn. 2016;8(5):715-721.

15. Winston RB, Massaro AV. Extracurricular Involvement Inventory: an instrument for assessing intensity of student involvement. J Coll Stud Personnel. 1987;28(2):169-175. 


\section{American Journal of Pharmaceutical Education 2019; 83 (4) Article 6950.}

16. Cohen D, Crabtree B. Qualitative research guidelines project. Robert Wood Johnson Foundation. http://www.qualres.org/ HomeAudi-3700.html. Accessed May 1, 2018.

17. Harry B, Sturges KM, Klinger JK. Mapping the process: an exemplar of process and challenge in grounded theory analysis. Educ Res. 2005;34(2):3-13.

18. Kiersma ME, Plake KS, Mason HL. Relationship between admission data and pharmacy student involvement in extracurricular activities. Am J Pharm Educ. 2011;75(8):Article 155.

19. Masella RS. The hidden curriculum: value added in dental education. J Dent Educ. 2006;70(3):279-283.
20. Jamal AA. Developing interpersonal skills and professional behaviors through extracurricular activities participation: a perception of King Abdulaziz University medical students. JKAU: Med Sci. 2012;19(4):3-24.

21. Carter N, Bryant-Lukosius D, DiCenso A, Blythe J, Neville AJ. The use of triangulation in qualitative research. Oncol Nurs Forum. 2014;41(5):545-547.

22. UNC Eshelman School of Pharmacy Outcomes and Core Competencies. https://pharmacy.unc.edu/academics/thepharmd/curriculum/outcomes-core-competencies/. Accessed May 5, 2019.

Appendix 1. Modified Extracurricular Involvement Inventory (EII) ${ }^{15}$

Student Name: Program Year: _ PY1 PY2 PY3 Name of Student Organization:

What type of organization is it? (Check one) Governance Honor society Professional fraternity Service or philanthropic Special interest Other, please specify:

In the last year, have you held an office in this organization or a position equivalent to one of the following offices? (Check one) President/Chairperson/Team Captain/Editor Vice-President/Vice Chairperson Treasurer Secretary Committee/Task Force/Project Chairperson I held no office or leadership position Other Office, please specify:

In the last four weeks, approximately how many hours have you been involved with this group or organization and its activities or programs? Average hours per week

Please respond to the following statements about your involvement in the above student organization or group. Check the one best response for each statement.

1. When I attended meetings, I expressed my opinion and/or took part in the discussions. Very often Often Occasionally Never I attended no meetings in the past four weeks.

The group/organization held no meetings in the past four weeks.

2. When I was away from members of the group/organization, I talked with others about the organization and its activities, or wore a pin, t-shirt/apparel, etc. to let others know about my membership.
Very often
Often
Occasionally
Never

3. When the group/organization sponsored a program or activity, I made an effort to encourage other students and/or members to attend.

The organization had no programs or activity during the past four weeks.

4. I volunteered or was assigned responsibility to work on something that the group/organization needed to have done. Very often Often Occasionally Never

5. I fulfilled my assigned duties or responsibilities to the group/organization on time. Very often___ Often__ Occasionally I had no duties or responsibilities except to attend meetings. 